\title{
"NAT URE"
}

\begin{abstract}
"The idea was put out by Norman Lockyer, the astronomer and spectroscopist, in 1868 . Huxley, Tyndall and nearly all the leading men of science of that day promised their support. Alexander [Macmillan], convinced that science would benefit by the devotion of a journal to it, did not hesitate ... so he helped Lockyer by calling upon his scientific friends, by publishing the paper, as Nature itself has lately recorded, 'for several decades at a financial loss', and, above all, by giving to the editor an absolute editorial independence. . . In 1943, they [the then joint editors] were able to write that 'today as much as ever, if Nature feels that, in the interest of science, any book, whether published by Macmillan's or not, should receive adverse criticism, then it gets it'... good to read in a naughty world".
\end{abstract}

Charles Morgan: The House of Macmillan (1843-1943)

$\mathrm{N}^{\mathrm{o}}$ OT even the present Editor's work is excepted; it is not so long since a book of which he was co-author received an adverse review in the columns of Nature. But, even Nature can make a mistake, not, one hopes, as often as those we see in the weekly and daily Press for there is not in Nature the same excuse of the deadline. There are some errors, however, which even the demands of time cannot excuse. The great Lord Northcliffe would never accept an excuse for an error of fact which could have been checked either by reference to the person concerned or elsewhere. He would, therefore, never have excused 'Atticus' for writing in the Sunday Times (London) of April 15 that "the Prime Minister's son, Maurice Macmillan, M.P. . . edits 'Nature', the scientific journal'. A small error one might think, which could do little harm. In fact, this wound, though unobtrusive like that of a stiletto, pierces deep and causes hidden injury, since it thrusts into the heart of the policy carried out by Nature itself and by Macmillan and Co., Ltd., its publishers, since its foundation. Some botanists claim that the least important characteristic of a plant is its name. Be that as it may, it is certainly true of editors. The first editor of Nature, the astrophysicist Sir Norman Lockyer, occupied the editorial chair for exactly half a century, from the foundation in 1869. The names of those who followed him and that of the present Editor are of no account. The main characteristic of Nature is that it is a scientific journal, known and used throughout the world of science. As such, it has always been, and still is, owned, but only owned, by the House of Macmillan. Scientists should be grateful, for although Macmillan do all they can to help and promote the journal they never attempt to influence, much less to interfere with, its policy. This is an attitude to publishing for which $N a t u r e$ can be grateful and the House of Macmillan proud.

It may be true that the least important characteristic of a plant is its name, but the recent statement in the Sunday Times (that it is the "Prime Minister's son" who edits Nature) shows that it is certainly not true that a rose by any other name smells just as sweet. For there is real and deep concern that it may in some sense be true that there is some outside interference in the editorial policy of Nature. After all, the Prime Minister himself is a member of the family which publishes the journal: his son is also a Member of Parliament. As Charles Morgan said, this is "a naughty world", and we have become suspicious of such coincidences. In these days when science is exerting such a profound influence on society it is all the more important that a scientific journal such as Nature should remain independent.

Nature must not only be independent, but also must be soen clearly to be so, for it goes to every part of the world where scientific research or teaching is being carried out. If the statement made in the Sunday Times were accepted as true in these countries it could be unfortunate and, in some cases, disastrous. 'Atticus' has made a silly error of fact. One day perhaps there will be a scientific Macmillan capable of editing Nature. There is no doubt that if there were he, too, would be as independent in his editorial policy from the rest of the family and from the firm that publishes Nature as is the present Editor and as have been the editors of the past.

Nearly twenty years ago Charles Morgan wrote the lines quoted at the beginning of this article. If he were alive to-day he could write them again with the same truth. 